\title{
THE DECREASING OF POROSITY DURING DIFFUSION TECHNOLOGY
}

\author{
Chien Huu NGUYEN, Tomáš DRAŽAN, Jakub HORNÍČEK, Hana KONEČNÁ, \\ Renata DVOŘÁKOVÁ, Oldřich NAVRÁTIL
}

\author{
Department of Mechanical Engineering, University of Defence in Brno, Czech Republic, EU \\ https://doi.org/10.37904/metal.2019.900
}

\begin{abstract}
The article deals with porosity of compound layers after gas and plasma nitriding. Experiments are focused on using of gas and plasma nitriding processes for surface treatment. Diffusion technologies were applied to steels C 35 (sample A1) and steel $41 \mathrm{Cr} 4$ (sample A2), which were subsequently evaluated by electron microscopy, GDOES, XRD and microhardness methods. Main task was to compare the surface hardness connected with chemical composition of steels and the porosity after plasma and gas nitriding and finally prepare the documentation of pores from surface and from cross sectional structure. Plasma and gas processes were applied for increasing of surface hardness of material in depth and improve mechanical and tribological properties. Mechanical and tribological properties of tested material were significantly increased.
\end{abstract}

Keywords: Alloying elements; nitrided layer; porosity; chemical composition

\section{INTRODUCTION}

The chemical-heat treatment is in many cases applied to already heat-treated steels, i.e. after heat-treatment process [1]. The aim of this paper is to achieve an enhanced of surface hardness, better wear resistance and reduced friction coefficient connected to specific surface morphology [2-5]. During chemical heat-treatment process the interstitial phases of nitrides and carbides of iron are created. The initial nitrides and carbides phases are created in grain boundaries, in the biggest defects well known as area defects. Generally, Fe nitrides and carbides caused only low increasing of microhardness. The final surface hardness after chemical heat treatment depends on two fundamental phenomenon $[4,6]$. During diffusion process the nitrides of iron are primarily created. This type of nitrides caused low increasing of microhardness. Main elements that caused increasing of mechanical properties are alloying elements as molybdenum, vanadium, aluminium or chrome. During diffusion process, two layers are mostly created. The compound layer created on the surface of steel is consisted of $\varepsilon-\mathrm{Fe} 2-3 \mathrm{~N}$ and $\mathrm{y}-\mathrm{Fe} 4 \mathrm{~N}$ phase $[5,8]$. The proportion of individual phases is dependent on carbon concentration in steel $[6,9,10]$. The compound layer has been very hard and brittle with good friction and anticorrosion properties $[4,8]$. Unfortunately, the porosity is very often presented in these surface compound layers. Moreover, the diffusion technology has remarkable influence on the surface $[9,10,11,12]$. This article describes the influence of type of nitriding technology to formation of areas of pores in surface compound layers. The aim of research was to compare two different diffusion technologies and their influence on the layer development and surface morphology. Chemical composition of steel was verified by GDOES/Bulk method on LECO SA 2000 spectrometer and local measurement of composition was carried out on SEM microscope Hitachi Tabletop 3000 equipped by XRD Oxford Instruments Stream-2. Microstructure was evaluated by electron microscopy method on Hitachi Tabletop 3000. Thickness and microhardness of nitrided layers were measured by microhardness method in accordance with DIN 50190 standard on automatic microhardness tester LECO LM 247 AT [13].

\section{EXPERIMENTAL PART}

Steel C35 (sample A1) and 41Cr4 (sample A2) in untreated ferrite-pearlite state were heat-treated. Tempering and quenching was performed due to reach different microstructure with different parameters of microhardness and different redistribution of atom in crystal lattice. 
Table 1 Conditions of heat-treatment

\begin{tabular}{|c|c|c|c|}
\hline \multirow{2}{*}{ Steel } & \multirow{2}{*}{ Sample } & Puenching & Process \\
\cline { 3 - 4 } & $\mathrm{A} 1$ & $860^{\circ} \mathrm{C}$, water & $600^{\circ} \mathrm{C}$, air \\
\hline C35 & $\mathrm{A} 2$ & $850^{\circ} \mathrm{C}$, oil & $600^{\circ} \mathrm{C}$, water \\
\hline $41 \mathrm{Cr} 4$ &
\end{tabular}

The steel structure was evaluated by electron microscopy on SEM Hitachi Tabletop 3000 before chemical heat-treatment. The structure after quenching is displayed in Figure 1. The conditions of heat-treatment process are given in Table 1.

The chemical composition of material was measured by GDOES/Bulk method on reference samples (Table 2). Glow discharge optical spectroscopy (GDOES) measurements were performed in LECO SA-2000, with argon glow discharge plasma excitation source, calibration of nitrogen: JK41-1N and NSC4A standards.

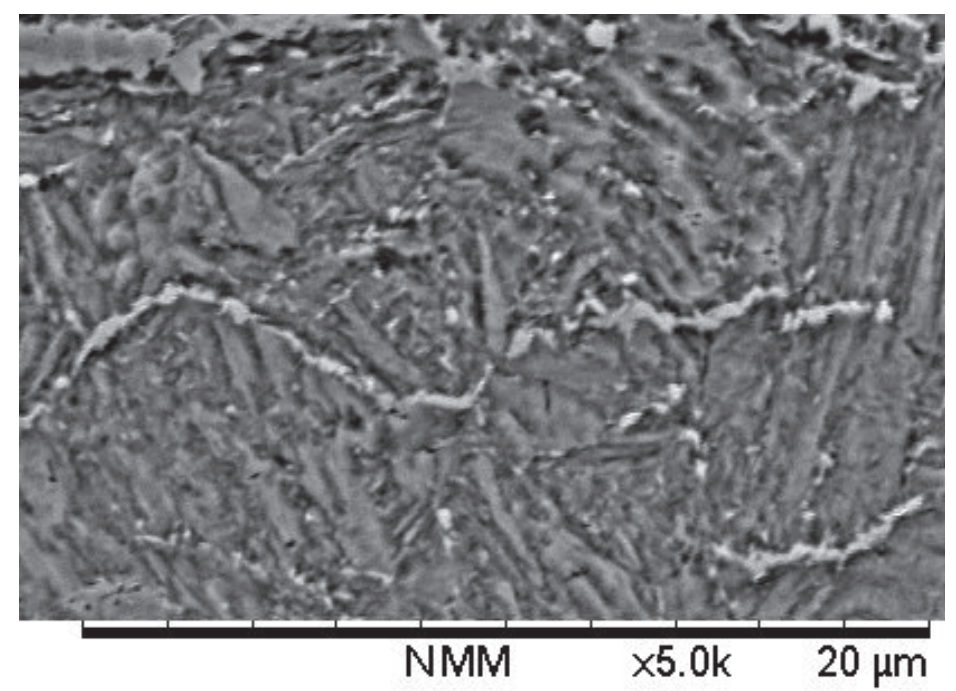

Figure 1 The chemically etched optical cross-sectional structure of sample A1 after heat-treatment

The microhardness of steel was evaluated by Vickers microhardness method on the automatic microhardness tester LM 247 AT LECO. Load set at $50 \mathrm{~g}$ and $10 \mathrm{~s}$ dwell time. This method was used for microhardness measurement of surface and the measurement of created diffusion layer in depth after gas and plasma nitriding process. A microhardness of heat-treated sample A1 was analysed to value $499 \pm 31 \mathrm{HV} 0.05$ after quenching and $266 \pm 6 \mathrm{HV} 0.05$ after tempering. In case of sample A2 it was reached the value of microhardness $625 \pm$ $35 \mathrm{HV} 0.05$ after quenching and $305 \pm 15 \mathrm{HV} 0.05$ after tempering.

After preparation and nital etching, the electron microscope Hitachi Tabletop 3000 was used for observation of surface morphology and cross-sectional structure documentation (Figure 1).

The thickness of created compound layer and the surface morphology after nitriding process were evaluated by electron microscope Hitachi Tabletop 3000 (Table 3, Figures 3, 4) equipped by XRD Oxford Instruments Stream-2.

\section{RESULTS AND DISCUSSION}

The main effort of experimental work was aimed at analysing of chemical and mechanical properties of the surface layers created by gas and plasma nitriding process. The chemical composition measurement showed the differences in concentration of alloy elements. 
Table 2 Chemical composition of selected steel

\begin{tabular}{|c|c|c|c|c|c|c|c|}
\hline \multirow{2}{*}{ Sample } & \multicolumn{7}{|c|}{ Chemical composition of steel $[\mathrm{w} \%(\mathrm{X})]$} \\
\cline { 2 - 8 } & $\mathrm{C}$ & $\mathrm{Mn}$ & $\mathrm{Si}$ & $\mathrm{Cr}$ & $\mathrm{Ni}$ & $\mathrm{Mo}$ & $\mathrm{Al}$ \\
\hline $\begin{array}{c}\mathrm{A} 1 \\
(\mathrm{C} 35)\end{array}$ & 0.36 & 0.68 & 0.33 & 0.08 & 0.04 & ----- & 0.003 \\
\hline $\begin{array}{c}\mathrm{A} 2 \\
(41 \mathrm{Cr} 4)\end{array}$ & 0.39 & 0.66 & 0.32 & $\mathbf{1 . 0 4}$ & 0.05 & ---- & 0.005 \\
\hline
\end{tabular}

Main task was to prove the differences in compound layer which is created after plasma and gas nitriding. Both processes caused different results according to working environment. Gas nitriding reached a higher depth of diffusion layer and the results are shown in Table 3.

Table 3 Depth of nitrided layers after gas and plasma nitriding

\begin{tabular}{|l|c|c|c|c|}
\hline \multirow{2}{*}{ Technology } & \multicolumn{4}{|c|}{ Depth $(\mu \mathrm{m})$} \\
\cline { 2 - 5 } & \multicolumn{2}{|c|}{ A1 } & \multicolumn{2}{c|}{ A2 } \\
\cline { 2 - 5 } & Compound layer & Diffusion layer & Compound layer & Diffusion layer \\
\hline Plasma nitriding 15 $\mathrm{h}$ & 5.36 & 0.05 & 5.27 & 0.22 \\
\hline Gas nitriding 15 & 9.72 & 0.08 & 10.18 & 0.24 \\
\hline
\end{tabular}

The difference in surface hardness of steels which is caused by concentration of chromium is given in Figure 2.

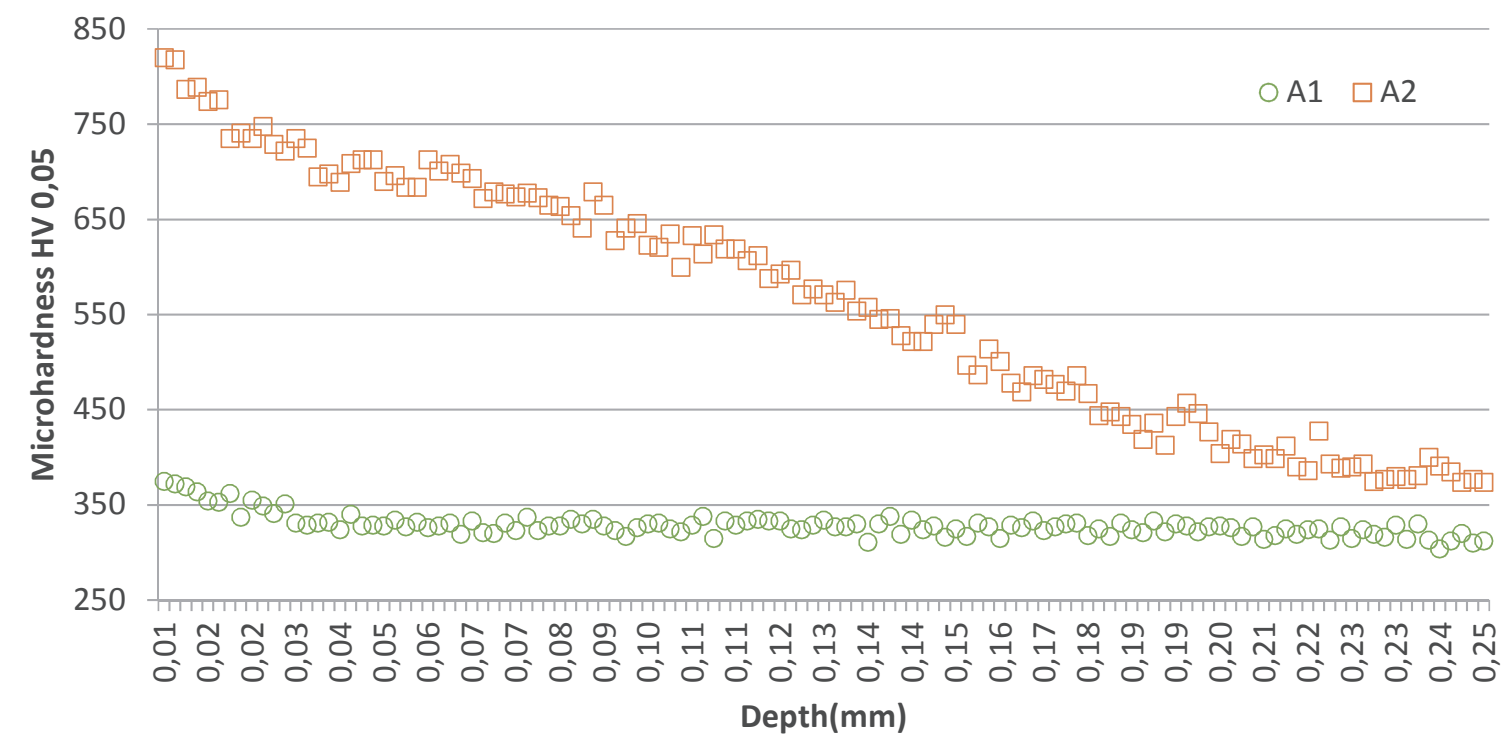

Figure 2 The increasing of surface microhardness caused by different chemical composition of samples after gas nitriding process

The surface hardness and trend of microhardness is connected with chemical composition of steel. The higher level of hardness it is possible to reach thank to chromium concentration and this results are given the trends in Figure 2.

In compound layers the porosity was created without difference of using technologies, i. g. present after plasma and gas nitriding. 


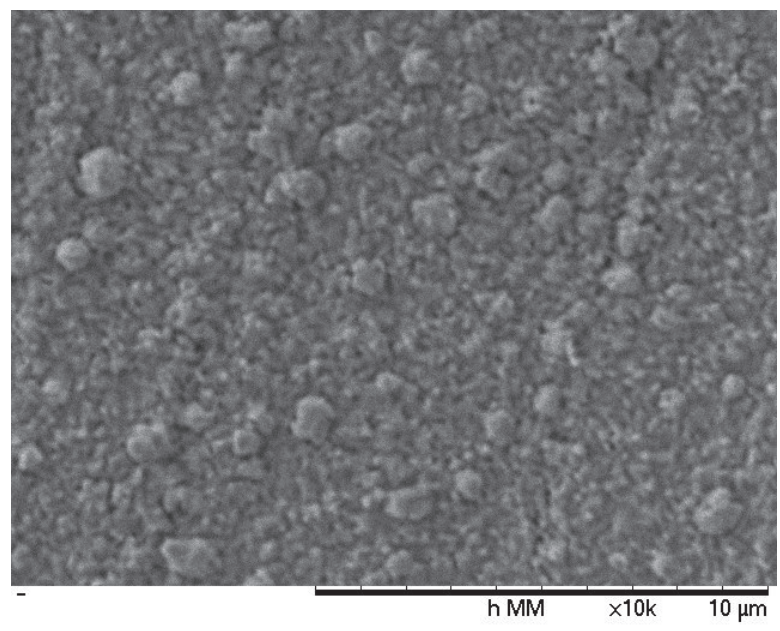

Figure 3a The surface morphology of $A 1$ after plasma nitriding process

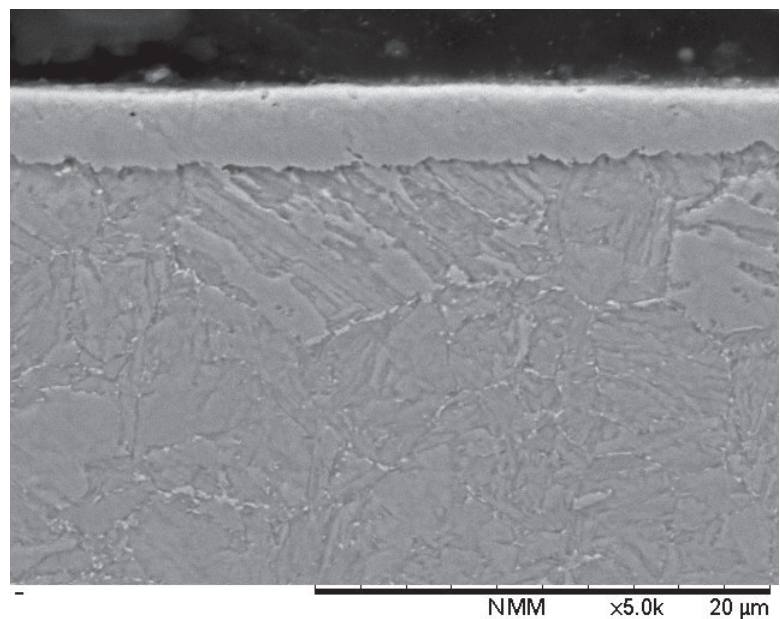

Figure 4a Cross-sectional structure of $\mathrm{A} 1$ after plasma nitriding process

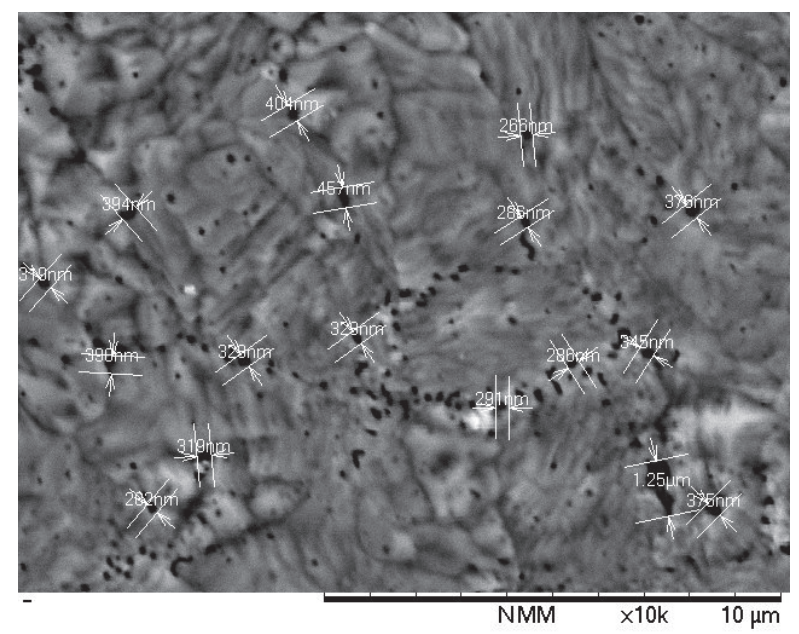

Figure $\mathbf{3 b}$ The surface morphology of A1 after gas nitriding process

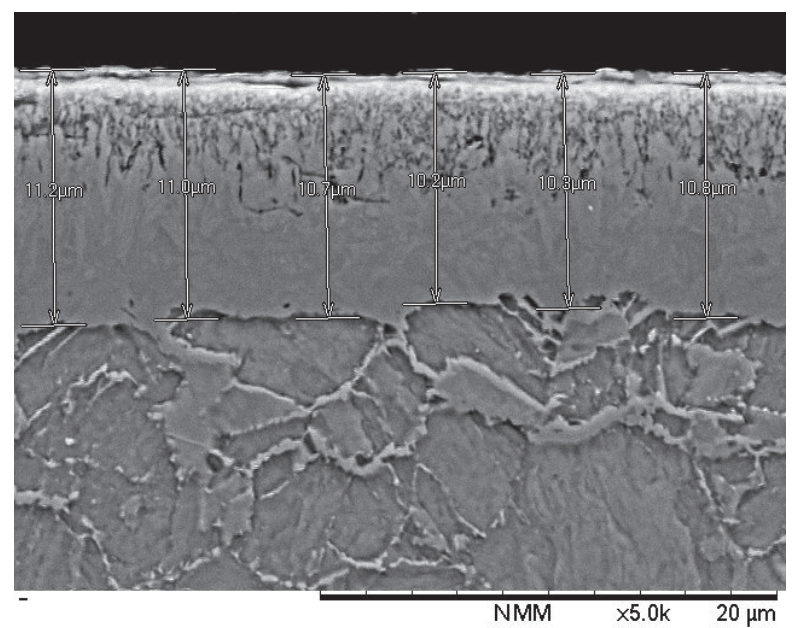

Figure 4b Cross-sectional structure of $A 1$ after gas nitriding process; overview of porosity

The porosity was significantly increased after gas nitriding (Figures $\mathbf{4 a}, \mathbf{4 b}$ ). The porosity was larger after gaseous technologies in all experiments. Pores were reduced after plasma technologies (Figure 4a). In compound layers created by plasma technologies there were presented only independently pores what is documented in Figure 4a. This result was confirmed by surface morphology (Figure 3a). In case of gas nitriding the porosity was visible from the surface of created compound layer (Figure $3 \mathbf{b}$ ). The results showed the interesting difference in surface microhardness. In dependent on chemical composition (concentration of alloying elements, chromium) the depth of microhardness was changeable. Chemical heat-treatment caused decreasing of initial microhardness of steel due to long time process of nitriding (Figure 2).

\section{CONCLUSION}

Gas nitriding process caused increasing of porosity in compound layer. It was reached significant reductions in case of using plasma nitriding process. It is obvious that compound layer is partially diffusion layer. The top part of compound layer was formed due to condensation of particles in atmosphere. We assume that the pores are predominantly formed in non-diffusion part of compound layer. The experiments showed that the chemical 
composition of surface compound layer after plasma and gas nitriding has different value of substitution elements. The chemical composition has not remarkable influence on porosity. The formation of pores is dependent on selected technology. The diffusion process is more effective in gaseous atmospheres than in plasma. After 15 hours' process of gas nitriding it was reached more suitable parameters of layers than after 15 hours' plasma process (Table 3). Finally, the concentration of molybdenum and chromium favorably influences diffusion process and help to increase the mechanical characteristics of diffusion layers. The created pores are suitable for storage of lubricants [3].

\section{ACKNOWLEDGEMENTS}

\section{The present research work was supported by the project The Development of Technologies, Design of Firearms, Ammunition, Instrumentation, Engineering of Materials and Military Infrastructure "VÝZBROJ (DZRO K201)" and Specific research SV 2019.}

\section{REFERENCES}

[1] POKORNY, Z., BARBORAK, O., HRUBY, V. Characteristics of plasma nitrided layers in deep holes. In: KOVOVE MATERIALY-METALLIC MATERIALS, 2012, Vol. 50, pp. 209-212.

[2] AKHLAGHI, M., STEINER, T., MEKA, S.R., LEINEWEBER, A., MITTEMEIJER, E.J. Lattice-parameter change induced by accommodation of precipitate/matrix misfit; misfitting nitrides in ferrite. In: Acta Materialia, 2015, vol. 98, pp. 254-262.

[3] MITTEMEIJER, E. J. Fundamentals of Nitriding and nitrocarburising. Berlin Heidelberg: Springer-Verlag, 2010.

[4] POKORNY, Z., KADLEC, J., HRUBY, V. Hardness of plasma nitrided layers created at different conditions. In: CHEMICKE LISTY, 2011, Vol. 105, pp. 717-720.

[5] MEHRER, H. Diffusion in Solids. Berlin: Springer-Verlag. 2007. 645 p.

[6] LEINEWEBER, A., GRESSMANN, T., MITTEMEIJER, E. J. Simultaneous Control of the Nitrogen and Carbon Activities during Nitrocarburising of Iron. In: Surface and Coating Technology, 2012, vol 206, pp. 2780-2791.

[7] POKORNY, Z., HRUBY, V. Plasma nitriding of deep narrow cavities. In: Key Engineering Materials, 2011, Vol. 465, pp. 267-270.

[8] KUSMIC, D., HRUBY, V., BACHAROVA, L. Corrosion resistance of surface treated 42CrMo4 steel. In: KOVOVE MATERIALY-METALLIC MATERIALS, 2016, Vol. 54, pp. 491-496.

[9] BARENYI, I., MAJERIK, J., POKORNY, Z. et. al. Material and technological investigation of machined surfaces of the OCHN3MFA steel. In: KOVOVE MATERIALY-METALLIC MATERIALS, 2019, Vol. 57, pp. 131-142.

[10] GASPAR, S., PASKO, J., MAJERNIK, J. Analysis of Change of Cast Macrostructure under Influence of Structural Adjustments of Ingate and its Impact upon Mechanical Properties. In: TEM JOURNAL-TECHNOLOGY EDUCATION MANAGEMENT INFORMATICS, 2017, Vol. 6, pp. 358-362.

[11] HORACEK, M., CHARVAT, O. PAVELKA, T. et al. Medical implants by using RP and investment casting technologies. In: CHINA FOUNDRY, 2011, Vol. 8, pp. 107-111.

[12] ZEMCIK, O., CHLADIL, J., SEDLAK, J. Changes in the surface layer of rolled bearing steel. In: Acta Polytechnika, 2015, Vol. 55, pp. 347-351.

[13] ČSN ISO 14577-1 METALIC MATERIALS - Instrumected indentation test for hardness and materials parameters - Part 1: Test method. 